\title{
A cash flow oriented EOQ model under permissible delay in payments
}

\author{
R. P. Tripathi ${ }^{1}$, S. S. Misra ${ }^{2}$, H. S. Shukla ${ }^{3}$ \\ ${ }^{1}$ Department of Mathematics, Dehradun Institute of Technology, Dehradun Uttarakhand, INDIA 248001 \\ ${ }^{2}$ DRDO, New Delhi, India \\ ${ }^{3}$ Department of Mathematics \& Statistics, DDU Gorakhpur University, Gorakhpur, U.P., INDIA 273009 \\ "Corresponding Author: e-mail: tripathi_rp0231@rediffmail.com
}

\begin{abstract}
This study presents an inventory model to determine an optimal ordering policy for non-deteriorating items and timedependent demand rate with delay in payments permitted by the supplier under inflation and time discounting. Mathematical models have been derived under two different situations, i.e. Case I: The permissible delay period is less than or equal to replenishment cycle period for settling the account and Case II: The permissible delay period is greater than replenishment cycle period for settling the account. This study determines the optimal cycle period and optimal payment period for item so that the annual total relevant cost is minimized. An algorithm is given to obtain optimal solution. The main purpose of this paper is to investigate the optimal (minimum) total present value of the costs over the time horizon H for both cases (i.e. case I and II). An algorithm is used to obtain the minimum total present value of the costs over the time horizon H. Finally, a numerical example and sensitivity analysis demonstrate the applicability of the proposed model and managerial insights.
\end{abstract}

Keywords: Pricing, Inventory, Non-Deterioration, Inflation, Delay in payments, Permissible, Replenishments, Cash flow.

\section{Introduction}

Sufficient work has been done by many authors for controlling the inventory of deteriorating and non-deteriorating items. In this study, we develop an inventory model for non-deteriorating items and time-dependent demand under inflation when delay in payment is permissible. In real life problems, particularly for controlling inventory, mathematical ideas have been used in different areas in recent years. Many authors have discussed inventory model for non-deteriorating items. However, there are certain substances in the deterioration that play an important role and items cannot be stored for a long time. In the traditional EOQ model, it is assumed that the customer must pay for the items as soon as the items are received. However, in practice, suppliers offer their customers a certain credit period without interest during the permissible delay time period. But if the payment is delayed beyond that period, a higher interest will be charged. Such a convenience is likely to motivate customers to order more quantities because paying later indirectly reduces the purchase cost. Thus, trade credit is an important source of financing for intermediate purchasers of goods and services. The permissible delay in payments reduces the buyer's cost of holding stock because it reduces the amount of capital invested in stock for the duration of the permissible period. Thus, it is a marketing strategy for the supplier to attract new customers who consider it to be a type of price reduction.

Hou and Lin (2009) developed a cash flow oriented EOQ model with deteriorating items under permissible delay in payments and the minimum total present value of the costs is obtained. In this paper all results have been obtained by taking constant net discount rate of inflation k. He obtained minimum total present value of the costs over the time horizon. Aggrawal et al. (2009) developed a model on integrated inventory system with the effect of inflation and credit period. In this model the demand rate is assumed to be a function of inflation. This EOQ model is applicable when the inventory contains trade credit that supplier give to the retailer. Tripathi and Misra (2010) developed EOQ model credit financing in economic ordering policies of non- deteriorating items with time- dependent demand rate in the presence of trade credit using a discounted cash-flow (DCF) approach. Jaggi et al. (2008) developed a model retailer's optimal replenishment decisions with credit- linked demand under permissible delay in payments. This paper incorporates the concepts of credit linked demand and developed a new inventory model under two levels of trade credit policy to reflect the real-life situation. An EOQ model under conditionally permissible delay in payments was 
developed by Huang (2007) and obtained the retailer's optimal replenishment policy under permissible delay in payments. Jaggi et al. (2007) developed an inventory model under two levels of trade credit policy by assuming the demand is a function of credit period offered by the retailer to the customers using discounted cash-flow (DCF) approach. Optimal retailer's ordering policies in the EOQ model for deteriorating items under trade credit financing in supply chain was developed by Mahata and Mahata (2009).In this paper authors obtained a unique optimal cycle time to minimize the total variable cost per unit time. Davis and Gaither (1985) developed EOQ models for firms offering a one-time opportunity to delay payments by their supplier for the order of an item. Goyal (1985) developed an EOQ model under condition of permissible delay in payments. He ignored the difference between the selling price and the purchase cost, and concluded that the economic replenishment interval and order quantity generally increases marginally under the permissible delay in payments. Dave (1985) corrected Goyal's model by assuming the fact that the selling price is necessarily higher than its purchase cost. Other many related articles can be found by Aggarwal and Jaggi (1995), Jamal et al. (1997), Sarker et al. (2000), Ouyang et al. (2006). Ghare and Schrader (1963) developed EOQ model with constant deterioration rate. Various types of inventory models for items deteriorating at a constant rate were discussed by Roy Chowdhury and Choudhuri (1983).

In a realistic product, life cycle demand is increasing with time during the growth phase. Chang and Dye (1999) developed an EOQ model with demand and partial backlogging. Naddar (1966) gives a detailed derivation of the total inventory cost for a constant demand rate lot size system, when the holding on hand in cost as $q^{m} t^{n}$ where $q$ denotes the amount of stock held and $t$, the length of time, it is kept, $m$ and $n$ being positive integers. Chung (1998) studied the same model as Goyal (1985) and presented an alternative approach to find a theorem to determine the EOQ under condition of permissible delay in payments. In Goyal's (1985) model, it is assumed that no deterioration is allowed to occur and the capacity of the warehouse is unlimited. Chu et al. (1998) considered the same model as Aggarwal and Jaggi (1995) to show that the total cost per unit time is piece wise convex and develop a solution procedure to improve that described by Aggarwal and Jaggi (1995).

This study develops an inventory model for time-dependent demand when a delay in payment is permissible. The effect of inflation and delay in payments are discussed. Mathematical models are also derived under two different circumstances, i.e. Case I: The credit period is less than or equal to the cycle time for settling the account and Case II: The credit period is greater than the cycle time for settling the account. The expressions for an inventory system's total cost are derived for the above two cases, also. Moreover, an algorithm is developed to determine the optimal number of replenishment cycle time and order quantity. Finally, we provide numerical example and sensitivity for illustration the theoretical results. This paper is the extension of Hou and Lin (2009) in which the deterioration and demand rate both are constant.

The rest of the paper is organized as follows: In section 2 we develop the mathematical formulation for the solution of, the total present value of the cost over the time horizon with regard to two different cases. An algorithm is developed in section 3 followed by numerical example in section 4 . In section 5 , describe sensitivity analysis to compare total present value of the costs and other process parameters, for different net discount rate of inflation. Five graphs are given to illustrate the results. Finally, we draw the conclusions ans future research in section 6.

\section{Mathematical Formulation}

To develop the mathematical model, the following assumptions are being made:

(1) The demand $R(t)$ for the item is a downward sloping function of the time. For simplicity, we assume that demand is a function of time i.e. $R(t)=(a+b t)$ where $a>0$ and $b>0$.

(2) Shortages are not allowed.

(3) Lead time is zero.

(4) The net discount rate of inflation rate is constant.

The inventory $I(t)$ at any time $t$ is depleted by the effect of demand only. Thus the variation of $I(t)$ with respect to ' $t$ ' is governed by the following differential equation:

$$
\frac{d I(t)}{d t}=-(a+b t), 0 \leq t \leq T=H / n
$$

With the boundary condition $I(T)=0$. The solution of equation (1) is given by

$$
I(t)=a(T-t)+\frac{b}{2}\left(T^{2}-t^{2}\right), \quad 0 \leq t \leq T=H / n
$$

The initial inventory (order quantity) after replenishment is given by

$$
Q=I(o)=a T+\frac{b T^{2}}{2}(T=H / n)
$$

The present value of the total replenishment cost is given by: 


$$
C_{1}=\sum_{j=0}^{n-1} A_{o} e^{-j k T}=A_{o}\left(\frac{1-e^{-k H}}{1-e^{-k T}}\right),(T=H / n)
$$

The present value of the total purchasing costs is given by

$$
C_{2}=c \sum_{j=0}^{n-1} I(o) e^{-j k T}=c Q\left(\frac{1-e^{-k H}}{1-e^{-k T}}\right),(T=H / n)
$$

The present value of the total holding costs over the time horizon $H$ is given by

$$
A=h \sum_{j=0}^{n-1} e^{-j k T} \int_{0}^{T} I(t) e^{-k t} d t=\frac{h}{k}\left\{Q+\frac{a\left(e^{-k T}-1\right)}{k}+\frac{b}{k}\left(T e^{-k T}+\frac{e^{-k T}-1}{k}\right)\right\}\left(\frac{1-e^{-k H}}{1-e^{-k T}}\right)
$$

Case I. $m \leq T=H / n$

The present value of the interest payable during the first replenishment cycle is given by

$$
\begin{gathered}
i_{p}=c I_{c} \int_{m}^{T} I(t) e^{-k t} d t=c I_{c}\left[Q\left(\frac{e^{-k m}-e^{-k T}}{k}\right)+a\left(\frac{T e^{-k T}-m e^{-k m}}{k}\right)+a\left(\frac{e^{-k T}-e^{-k m}}{k^{2}}\right)\right. \\
\left.+\frac{b}{2}\left\{\left(\frac{T^{2} e^{-k T}-m^{2} e^{-k m}}{k}\right)+2\left(\frac{T e^{-k T}-m e^{-k m}}{k^{2}}\right)+2\left(\frac{e^{-k T}-e^{-k m}}{k^{3}}\right)\right\}\right]
\end{gathered}
$$

Hence, the present value of the total interest payable over the time horizon $H$ is given by

$$
I_{p}=\sum_{j=0}^{n-1} i_{p} e^{-j k T}=i_{p}\left(\frac{1-e^{-k H}}{1-e^{-k T}}\right)
$$

Also, the present value of the interest earned during the first replenishment cycle is

$$
E=c I_{e} \int_{0}^{T} R(t) t e^{-k t} d t=c I_{e}\left[a\left(\frac{-T e^{-k T}}{k}+\frac{1-e^{-k T}}{k^{2}}\right)-b\left\{\frac{T^{2} e^{-k T}}{k}+\frac{2 T e^{-k T}}{k^{2}}+\frac{2\left(e^{-k T}-1\right)}{k^{3}}\right\}\right]
$$

Thus the present value of the total interest earned over the time horizon $H$ is

$$
E_{1}=\sum_{j=0}^{n-1} E e^{-j k T}=E\left(\frac{1-e^{-k H}}{1-e^{-k T}}\right)
$$

Therefore, the total present value of the costs over the time horizon $H$ is

$$
Z_{1}(n)=C_{1}+C_{2}+A+I_{p}-E_{1}
$$

Differentially equation (11) partially with respect ' $n$ ' two times, we get

$$
\frac{\partial^{2} Z_{1}(n)}{\partial n^{2}}>0
$$

Consequently, for fixed ' $H$ ' $Z_{1}(n)$ is a convex function of ' $n$ '. Thus there exists a unique value of ' $n$ ' which minimizes $Z_{1}(n)$.

Case II. $m>T=H / n$

The interest earned in the first cycle is the interest during the time period $(0, T)$ plus the interest earned from the cash invested during the time period $(T, m)$ after the inventory is exhausted at time $T$ and it is given by

$$
\begin{aligned}
& E_{2}=c I_{e}\left[\int_{0}^{T} R(t) t e^{-k t} d t+(m-T) e^{-k T} \int_{0}^{T} R(t) d t\right] \quad(T=H / n) \\
& =c I_{e}\left[a\left(\frac{-T e^{-k T}}{k}+\frac{1-e^{-k T}}{k^{2}}\right)-b\left\{\frac{T^{2} e^{-k T}}{k}+\frac{2 T e^{-k T}}{k^{2}}+\frac{2}{k^{3}}\left(e^{-k T}-1\right)\right\}+(m-T) Q e^{-k T}\right]
\end{aligned}
$$

Hence, the present value of the total interest earned over the time horizon $H$ is

$$
E_{3}=\sum_{j=1}^{n-1} E_{2} e^{-j k T}=E_{2}\left(\frac{1-e^{-k H}}{1-e^{-k T}}\right)
$$


The total present value of the costs $Z_{2}(n)$ is given by

$$
Z_{2}(n)=C_{1}+C_{2}+A-E_{3}
$$

Differentially equation (14) partially with respect 'n' two times, we get

$$
\frac{\partial^{2} Z_{2}(n)}{\partial n^{2}}>0
$$

Consequently, for fixed ' $H$ ' $Z_{2}(n)$ is a convex function of ' $n$ '. Thus there exists a unique value of ' $n$ ' which minimizes $Z_{2}(n)$. Thus, if we draw curve between $Z_{1}(n)$ and $Z_{2}(n)$ and ' $n$ ' the curve is convex.

$\mathrm{Z}_{2}(\mathrm{n})$

Note: Mathematica software is used to differentiate $Z_{1}(n)$ and $Z_{2}(n)$ with respect to ' $n$ '.

$$
\begin{aligned}
& \text { At } m=T=H / n, \text { we find } Z_{1}(n)=Z_{2}(n), \text { we have } \\
& Z(n)= \begin{cases}Z_{1}(n), & \text { if } T=H / n \geq m \\
Z_{2}(n), & \text { if } T=H / n \leq m\end{cases}
\end{aligned}
$$

Based on the above discussion, the following algorithm is developed to derive the optimal $n, T, Q$ and $Z(n)$ values.

Note that there are many different ways to calculate $Z_{1}(n)$ and $Z_{2}(n)$ such as Goyal (1985), Aggarwal and Jaggi (1995) . For simplicity, we use Goyal's approach throughout this paper.

\section{Algorithm}

Step 1: Choose a discrete variable $n$ first, where $n$ is any integer equal or greater than 1 .

Step 2: If $m \leq T=H / n$, for different integer $n$ values, obtain $Z_{1}(n)$ from (11) if $m \geq T=H / n$ for different integer $n$ values obtain $Z_{2}(n)$ from (14).

Step 3: Repeat step 1 and 2 for all possible values of $n$ with $m \leq T=H / n$ until the minimum $Z_{1}(n)$ is found from equation (11) and let $n_{1}^{*}=n$. For all possible values of $n$ with $m \geq T=H / n$ until the minimum $Z_{2}(n)$ is found from equation (14) and let $n_{2}^{*}=$ $n$. The $n_{1}^{*}$ and $n_{2}^{*}, Z_{1}\left(n_{1}^{*}\right)$ and $Z_{2}\left(n_{2}^{*}\right)$ values from the optimal solution.

Step 4: Select the optimal number of replenishment $n^{*}$ such that

$$
Z\left(n^{*}\right)=\min \begin{cases}Z_{1}\left(n_{1}^{*}\right), & \text { if } T=H / n_{1}^{*} \geq m \\ Z_{2}\left(n_{2}^{*}\right), & \text { if } T=H / n_{2}^{*} \leq m\end{cases}
$$

Thus, optimal order quantity $Q^{*}$ is obtained by putting $n^{*}$ into (3) and optimal cycle time $T^{*}$ is $T^{*}=H / n^{*}$.

\section{Numerical Example}

To illustrate the results of the model developed in this study an example is given with the following data : $a=500$ unit, $b=0.4$ unit, $A_{o}=\$ 50 /$ order, the holding cost excluding interest charges, $\mathrm{h}=\$ 2.0 / \mathrm{unit} / \mathrm{year}$, the per unit item cost, $c=\$ 10 /$ unit; the net discount rate of inflation, $k=\$ 0.10 / \$ /$ year, the interest charged per $\$$ in stocks per year by the supplier, $I_{c}=\$ 0.15 / \$ /$ year, the interest earned per $\$$ per year, $I_{e}=\$ 0.12 / \$ /$ year and the planning horizon, $H$ is 5 year. The permissible delay in settling account, $m$ $=70$ days $=70 / 365$ years. Using the algorithm, we have the computational results shown in Table 1 . The sources of data in our numerical results and figures have been collected from our industrial visit during the early visit of year 2010. In the numerical example we see that the case I is optimal option in credit policy. The minimum total present value of costs is obtained when the number of replenishment, $n$, is 19 . With 19 replenishments, the optimal (minimum) cycle time is 0.263 year, the optimal (minimum) order quantity, $Q=131.51$ units and the optimal (minimum) total present value of costs, $Z=\$ 20930.24$.This means that the marketing department, production department and finance department are in an enterprise jointly to find the policy. Therefore, the policy involves inventory, financing and marking issue. So, we investigate that this model is very important and valuable to the enterprise. 
Table 1. Numerical results

\begin{tabular}{ccccc}
\hline Case & Order No. & Cycle Time ' $T$ & Order Quantity $(Q)$ & Total costs \\
& $(n)$ & year & units & $Z(n)$ \\
\hline I & 15 & 0.333 & 166.52 & 20960.80 \\
& 16 & 0.312 & 156.02 & 20943.39 \\
& 17 & 0.294 & 147.02 & 20934.34 \\
& 18 & 0.274 & 137.02 & 20932.01 \\
& $19^{*}$ & $0.263^{*}$ & $131.51^{*}$ & $20930.24 *^{*}$ \\
20 & 0.250 & 125.01 & 20949.52 \\
& 21 & 0.238 & 119.01 & 20965.05 \\
& 22 & 0.227 & 113.51 & 20983.70 \\
& 23 & 0.217 & 108.51 & 21004.68 \\
& 24 & 0.208 & 104.01 & 21027.16 \\
II & 0.200 & 100.01 & 21053.66 \\
& 25 & 9.192 & 96.01 & 21073.65 \\
& 26 & 0.185 & 89.51 & 21093.21 \\
& 27 & 0.179 & 86.01 & 21119.20 \\
& 28 & 0.172 & 83.51 & 21140.08 \\
& 29 & 0.167 & 80.51 & 21167.95 \\
& 30 & 0.161 & 78.00 & 2186.14 \\
& 31 & 0.156 & 76.00 & 21238.98 \\
& 32 & 0.152 & 73.50 & 21265.50 \\
& 33 & 0.147 & 71.50 & 21414.76 \\
& 34 & 0.143 & 62.50 & 21575.28 \\
& 35 & 0.125 & 55.50 & 21740.40 \\
& 40 & 0.111 & 50.00 & 22097.24 \\
\hline
\end{tabular}

* Optimal solution

\section{Sensitivity Analysis}

Taking all the parameters as in the above numerical example, the variation of the optimal solution for different values of net discount rate of inflation $\mathrm{k}$ is given in Table 2.

Table 1. Variation of the optimal solution for different values of net discount rate of inflation $k$

\begin{tabular}{|c|c|c|c|c|c|c|c|}
\hline $\mathrm{n}$ & $\mathrm{k} \rightarrow$ & 0.1 & 0.12 & 0.14 & 0.16 & .18 & 0.20 \\
\hline \multirow[t]{6}{*}{15} & $\mathrm{C}_{1}$ & 600.69 & 575.90 & 552.60 & 530.66 & 510.00 & 490.54 \\
\hline & $\mathrm{C}_{2}$ & 20005.25 & 19179.94 & 18403.66 & 17673.10 & 16985.18 & 16337.06 \\
\hline & $\mathrm{A}$ & 658.36 & 629.89 & 603.12 & 577.94 & 554.26 & 531.96 \\
\hline & $I_{p}$ & 87.47 & 83.46 & 79.70 & 76.17 & 72.86 & 69.74 \\
\hline & $\mathrm{E}_{1}$ & 390.96 & 373.18 & 356.49 & 340.83 & 326.12 & 312.29 \\
\hline & $Z(n)$ & 20960.80 & 20096.01 & 19282.58 & 18517.04 & 17796.18 & 17117.01 \\
\hline \multirow[t]{6}{*}{16} & $\mathrm{C}_{1}$ & 640.45 & 613.90 & 588.93 & 565.43 & 543.31 & 522.47 \\
\hline & $\mathrm{C}_{2}$ & 19984.53 & 19156.09 & 18376.97 & 17643.83 & 16953.56 & 16303.28 \\
\hline & $\mathrm{A}$ & 617.24 & 590.41 & 565.22 & 541.54 & 519.27 & 498.32 \\
\hline & $I_{p}$ & 67.60 & 64.50 & 61.59 & 58.86 & 56.29 & 53.88 \\
\hline & $E_{1}$ & 366.43 & 349.79 & 334.17 & 319.52 & 305.75 & 292.80 \\
\hline & $\mathrm{Z}(\mathrm{n})$ & 20943.39 & 20075.11 & 19258.53 & 18490.14 & 1776.69 & 17085.16 \\
\hline \multirow[t]{6}{*}{17} & $\mathrm{C}_{1}$ & 679.05 & 650.78 & 624.21 & 599.20 & 575.65 & 553.48 \\
\hline & $\mathrm{C}_{2}$ & 19966.80 & 19135.69 & 18354.14 & 17618.78 & 16926.50 & 16274.39 \\
\hline & $\mathrm{A}$ & 582.06 & 556.63 & 532.78 & 510.38 & 489.33 & 469.54 \\
\hline & $I_{p}$ & 51.82 & 49.44 & 47.20 & 45.11 & 43.14 & 41.29 \\
\hline & $E_{1}$ & 345.39 & 329.72 & 315.02 & 301.23 & 288.26 & 276.08 \\
\hline & $\mathrm{Z}(\mathrm{n})$ & 20934.34 & 20062.82 & 19243.30 & 18472.25 & 17746.36 & 17062.62 \\
\hline
\end{tabular}


Table 2. (cont'd) Variation of the optimal solution for different values of net discount rate of inflation $k$

\begin{tabular}{|c|c|c|c|c|c|c|c|}
\hline $\mathrm{n}$ & $\mathrm{k} \rightarrow$ & 0.1 & 0.12 & 0.14 & 0.16 & .18 & 0.20 \\
\hline \multirow[t]{6}{*}{18} & $\mathrm{C}_{1}$ & 729.89 & 679.46 & 668.84 & 641.91 & 616.57 & 592.70 \\
\hline & $\mathrm{C}_{2}$ & 19947.14 & 19113.06 & 18328.82 & 17591.00 & 16896.48 & 16242.34 \\
\hline & $\mathrm{A}$ & 543.05 & 519.17 & 496.80 & 475.83 & 456.13 & 437.61 \\
\hline & $I_{p}$ & 35.93 & 34.27 & 32.72 & 31.27 & 29.90 & 28.62 \\
\hline & $\mathrm{E}_{1}$ & 322.00 & 307.41 & 293.73 & 280.88 & 268.81 & 257.46 \\
\hline & $\mathrm{Z}(\mathrm{n})$ & 20932.01 & 20056.54 & 19233.45 & 18459.13 & 17730.28 & 17043.81 \\
\hline \multirow[t]{6}{*}{19} & $\mathrm{C}_{1}$ & 757.92 & 726.15 & 696.28 & 668.18 & 641.73 & 616.82 \\
\hline & $\mathrm{C}_{2}$ & 19934.82 & 19099.18 & 18313.52 & 17574.41 & 16878.72 & 16223.51 \\
\hline & $\mathrm{A}$ & 518.59 & 496.17 & 475.05 & 455.18 & 436.47 & 418.85 \\
\hline & $I_{p}$ & 28.04 & 26.75 & 25.54 & 24.40 & 23.34 & 22.34 \\
\hline & $E_{1}$ & 309.13 & 295.14 & 282.01 & 269.68 & 258.10 & 247.22 \\
\hline & $\mathrm{Z}(\mathrm{n})$ & 20930.24 & 20053.11 & 19228.38 & 18452.49 & 17722.14 & 17034.29 \\
\hline \multirow[t]{6}{*}{20} & $\mathrm{C}_{1}$ & 796.82 & 763.32 & 731.82 & 702.20 & 674.31 & 648.06 \\
\hline & $\mathrm{C}_{2}$ & 19922.00 & 19084.44 & 18297.03 & 17556.34 & 16859.20 & 16202.68 \\
\hline & $\mathrm{A}$ & 493.15 & 471.76 & 451.64 & 432.70 & 414.88 & 398.10 \\
\hline & $I_{p}$ & 19.68 & 18.78 & 17.93 & 17.13 & 16.38 & 15.67 \\
\hline & $E_{1}$ & 293.91 & 280.62 & 268.15 & 256.44 & 245.44 & 235.10 \\
\hline & $\mathrm{Z}(\mathrm{n})$ & 20937.75 & 20057.68 & 19230.27 & 18451.92 & 17719.33 & 17029.40 \\
\hline \multirow[t]{6}{*}{21} & $\mathrm{C}_{1}$ & 836.49 & 801.23 & 768.08 & 736.90 & 707.55 & 679.92 \\
\hline & $\mathrm{C}_{2}$ & 19910.18 & 19070.85 & 18281.83 & 17539.67 & 16841.20 & 16183.47 \\
\hline & $\mathrm{A}$ & 469.70 & 449.26 & 430.04 & 411.97 & 394.97 & 378.96 \\
\hline & $I_{p}$ & 13.00 & 12.40 & 11.84 & 11.31 & 10.82 & 10.35 \\
\hline & $E_{1}$ & 279.86 & 267.21 & 255.35 & 244.21 & 233.74 & 223.91 \\
\hline & $\mathrm{Z}(\mathrm{n})$ & 20949.52 & 20066.53 & 19236.44 & 18455.64 & 17720.80 & 17028 \\
\hline \multirow[t]{6}{*}{22} & $\mathrm{C}_{1}$ & 876.55 & 839.50 & 804.68 & 771.93 & 741.11 & 712.09 \\
\hline & $\mathrm{C}_{2}$ & 19899.36 & 19058.41 & 18267.91 & 17524.41 & 16824.72 & 16165.88 \\
\hline & $\mathrm{A}$ & 448.23 & 428.65 & 410.27 & 392.98 & 376.74 & 361.44 \\
\hline & $I_{p}$ & 7.89 & 7.53 & 7.19 & 6.87 & 6.56 & 6.28 \\
\hline & $E_{1}$ & 266.97 & 254.92 & 243.61 & 232.99 & 223.01 & 213.63 \\
\hline & $\mathrm{Z}(\mathrm{n})$ & 20965.05 & 20079.17 & 19246.44 & 18463.21 & 17726.12 & 17032.06 \\
\hline
\end{tabular}

The data obtained clearly shows those individual optimal solutions different from each other for different values of net discount rate of inflation ' $k$ ' and number of replenishments during ' $n$ '. All the observations can be summed up as follows:

(i). An increase in the net discount rate of inflation ' $k$ ', decrease of total replenishment cost , in total purchasing cost, in total holding cost, in total interest payable, in total interest earned and also decrease in total present value of the costs, $\mathrm{C}_{1}, \mathrm{C}_{2}, \mathrm{~A}, \mathrm{I}_{\mathrm{p}}$, $\mathrm{E}_{1}, \mathrm{Z}(\mathrm{n}) \cdot$.respectively.

(ii).If number of replenishment ' $n$ ' increases, then there is increase in the total replenishment cost $\mathrm{C}_{1}$, but the total purchasing costs $\mathrm{C}_{2}$, total holding cost ' $\mathrm{A}$ ', total interest payable ' $\mathrm{I}_{\mathrm{p}}$ ', and the interest earned ' $\mathrm{E}_{1}$ ' decreases, keeping net discount rate of inflation ' $k$ ' constant. But total present value of the $\operatorname{cost} Z(n)$ decreases from $n=15$ to $n=19$ and then increases from $n=20$ and on wards for $\mathrm{k}=0.1,0.12$, and 0.14 ; and $\mathrm{Z}(\mathrm{n})$ decreases from $\mathrm{n}=15$ to $\mathrm{n}=20$ and increases from $\mathrm{n}=21$ and onwards for $\mathrm{k}=$ $0.16,0.18$, and 0.2 .

The figures between number of replenishment ' $n$ ' and the total present value of the cost $Z(n)$ for different values of net discount rate of inflation ' $\mathrm{k}$ ' is given below (Figures 1 to 5): 


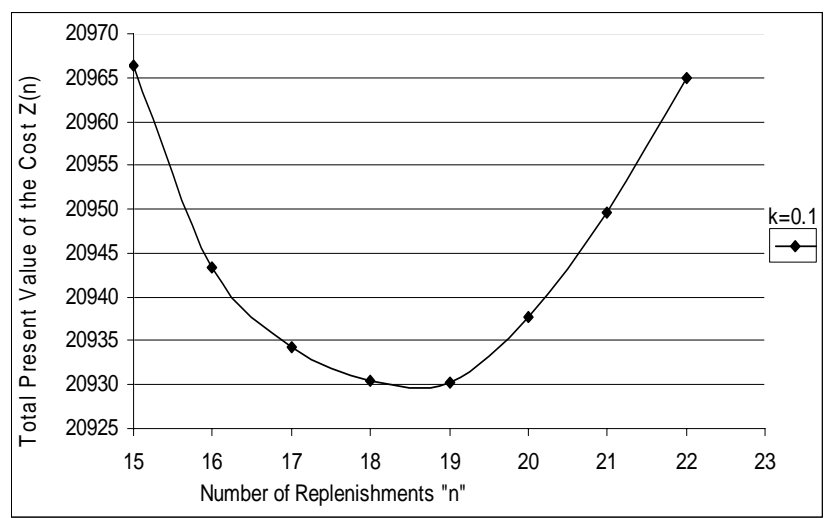

Figure 1.Plot of ' $\mathrm{n}$ ' against $\mathrm{Z}(\mathrm{n})$, for $\mathrm{k}=0.1$

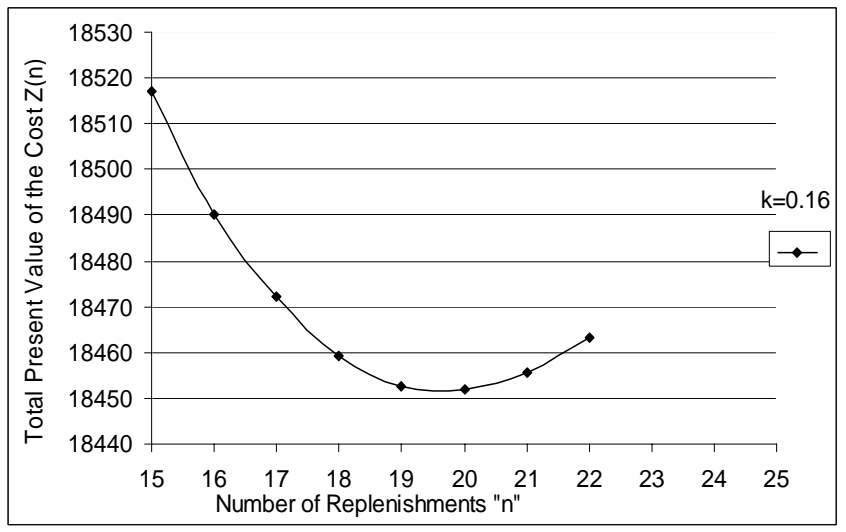

Figure 3.Plot of ' $\mathrm{n}$ ' against $\mathrm{Z}(\mathrm{n})$, for $\mathrm{k}=0.16$

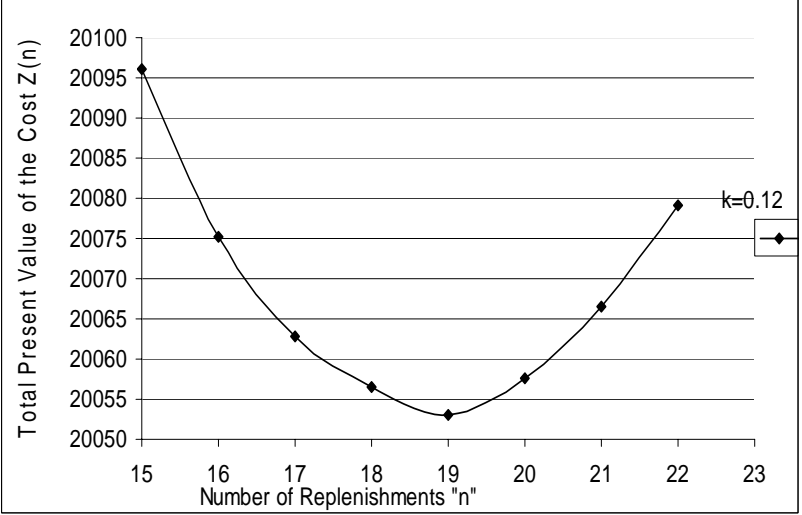

Figure 2.Plot of ' $\mathrm{n}$ ' against $\mathrm{Z}(\mathrm{n})$, for $\mathrm{k}=0.12$

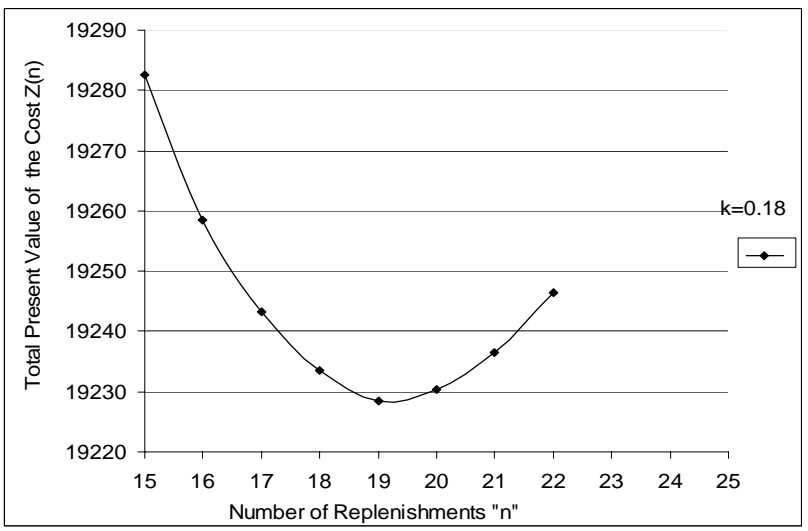

Figure 4.Plot of ' $n$ ' against $Z(n)$, for $k=0.18$

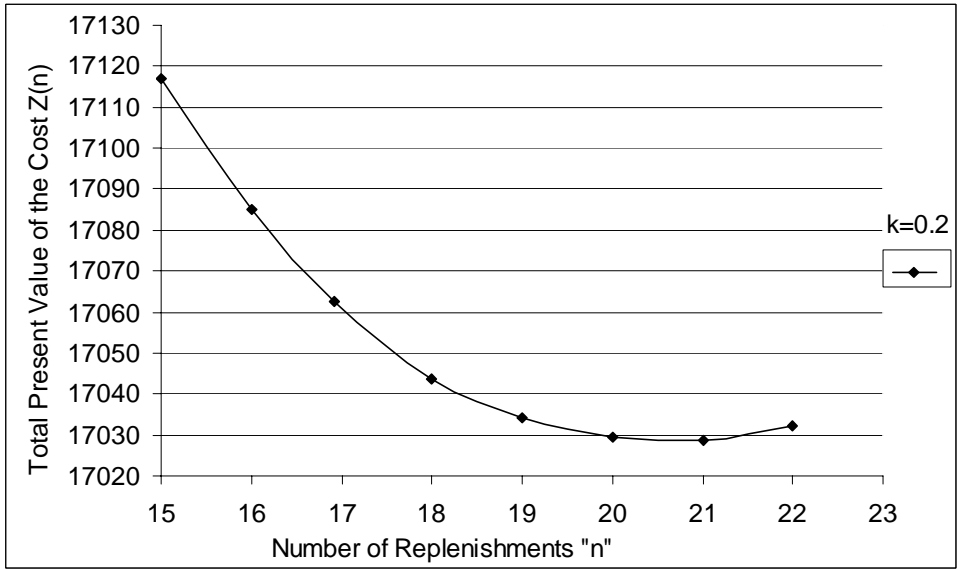

Figure 5.Plot of 'n' against $Z(n)$, for $\mathrm{k}=0.2$

\section{Conclusion and Future research}

This study develops an inventory model for non-deteriorating items over a finite planning horizon, when the supplier provides a permissible delay in payments. The model considers the effects of inflation and permissible delay in payments. In this study we have presented an optimal solution procedure to obtain the optimal number of replenishment, cycle time and order quantity to minimize the total present value of costs. Numerical example is given to illustrate the model to case I and II. We obtained the case I is optimal (minimum) option in credit policy. The minimum total present value of the costs is obtained when the number of replenishments, $\mathrm{n}$ is 19 .With 19 replenishments, the optimal (minimum) order quantity, $\mathrm{Q}=131.51$ units and the optimal (minimum) total present value of the costs, $Z=\$ 20930.24$.If demand rate is constant, this model is the same as Hou and Lin (2009) model for deterioration rate is equal to zero. The model proposed in this paper can be extended in several ways. For instance, we may extend the time dependent deterioration rate. We could also consider the demand as a function of quantity as 
well as quadratic time varying. Finally, we could generalize the model with stochastic market demand when the supplier provides a permissible delay in payments and cash discount.

\section{Notations}

$I(t) \quad$ : Inventory at any time $t$

$Q \quad$ : Order quantity, units/cycle

$H \quad$ : Length of planning horizon

$T \quad$ : Replenishment cycle time

$n \quad$ : Number of replenishment during the planning horizon, $n=H / n$

$R(t) \quad$ : Demand rate per unit time, and $R(t)=a+b t, a>0, b>0$

$A_{o} \quad:$ Order cost at time' $t$ ' is zero, $\$$ /order

c : Per unit cost of the item, \$/unit

$h \quad:$ Inventory holding cost per unit per unit time excluding interest charges, \$/unit/unit time

$r \quad$ : Discount rate represent the time value of money

$f \quad:$ Inflation rate

$k \quad:$ The net discount rate of inflation $(k=r-f)$

$I_{e} \quad:$ The interest earned per dollar in stocks per unit time by the supplier

$I_{c} \quad:$ The interest charged per dollar in stocks per unit time by the supplier, $I_{c} \geq I_{e}$

$m \quad$ : The permissible delay in settling account

$i_{p} \quad$ : Interest payable during the first replenishment cycle

$Z_{1}(n)$ : The total present value of the cost over the time horizon $H$, for $m \leq T=H / n$

$Z_{2}(n)$ : The total present value of the cost for $m>T=H / n$

$E \quad$ : The interest earned during the first replenishment cycle

$E_{1} \quad$ : The present value of the total interest earned over the time horizon

$I_{p} \quad$ : The total interest payable over the time horizon $H$

\section{Acknowledgement}

The authors greatly acknowledge the anonymous referees for their constructive and valuable suggestions to improve the quality of the paper.

\section{References}

Agrawal,R. ,Rajput, D. and Varshney, N.K. 2009. Integrated inventory system with the effect of inflation and credit period. International Journal of Applied Engineering Research. Vol 4, No.11, pp. 2334-2348.

Aggarwal, S.P. and Jaggi, C.K. 1995. Ordering policies of deteriorating items under permissible delay in payments, Journal of Operational Research Society, Vol 46, pp.458-462.

Chang, H.J. and Dye, C.Y.1999. An EOQ model for deteriorating items with time varying demand and partial backlogging, Journal of the Operational Research Society. Vol 50,No.11, pp.1176-1182.

Chu, P., Chung, K.J. and Lan, S.P. 1998. Economic order quantity of deteriorating items under permissible delay in payments, Computers and Operations Research. Vol 25, pp.817-824.

Chung, K.H. 1998. A theorem on the determination of economic order quantity under conditions of permissible delay in payments, Computers and Operations Research. Vol 25,pp. 49-52.

Davis, R.A. and Gaither. 1985. Optimal ordering policies under condition of extended payment privileges, Management Science, Vol 31, pp.499-509.

Dave, U. 1985. On economic order quantity under conditions of permissible delay in payments by Goyal, Journal of Operational Research Society, Vol 36, pp.1069.

Ghare, P.M. and Shrader, G.F. 1963. A model for exponentially decaying inventory. J. Ind. Eng., Vol 14, pp.238-243.

Goyal, S.K. 1985. Economic order quantity under conditions of permissible delay in payments, Journal of the Operational Research Society, Vol 36, pp.335-338.

Hou, K.L. and Lin, L. C. 2009. A cash flow oriented EOQ model with deteriorating items under permissible delay in payments.

Journal of Applied Sciences. Vol 9 ,No.9, pp.1791-1794.

Huang,Y.F. 2007. Economic order quantity under conditionally permissible delay in payments. European Journal of Operational Research. Vol 176, pp. 911-924.

Jaggi,C.K., Goyal,S.K. and Goel,S.K. 2008. Retailer's optimal replenishment decisions with credit-linked demand under permissible delay in payments. European Journal of Operational Research. Vol 190, pp. 130-135. 
Jaggi,C.K. Aggarwal,K.K. and Goel,S.K. 2007. Retailer's optimal ordering policy under two stage trade credit financing. Advanced Modeling and Optimization. Vol 9, No.1, pp. 67-80.

Jamal, A.A.M., Sarker, B.R. and Wang, S. 1997. An ordering policy for deteriorating items wills allowable shortage and permissible delay in payments. Journal of Operational Research Society, Vol 48, pp.826-833.

Mahata, G.C. and Mahata, P. 2009. Optimal retailer's ordering policies in the EOQ model for deteriorating items under trade credit financing in supply chain. International Journal of Mathematical, Physical and Engineering Sciences. Vol 3 No.1, pp. 1-7.

Naddor, E. 1966. Inventory Systems. Wiley, New York.

Ouyang, L.Y., Wu, K.S. and Yang, C.T. 2006. A study on an inventory model for non-instantaneous deteriorating items with permissible delay in payments, Comput. Ind. Eng., Vol 51, pp. 637-651.

Roychowdhury, M. and Chaudhuri, K.S. 1983. An order level inventory mode for deteriorating items with finite rate of replenishment, Opsearch. Vol 20, pp.99-106.

Sarker, B.R., Jamal, A.A.M. and Wang, S. 2000. Supply chain model for perishable product under inflation and permissible delay in payments. Comput. Operat. Res.,Vol 27, pp.59-75.

Tripathi,R.P. and Misra, S.S. 2010. Credit financing in economic ordering policies of non- deteriorating items with time dependent demand rate. International Review of Business and Finance. Vol 2, No. 1, pp. 47-55.

\section{Biographical notes}

R.P.Tripathi is an Assistant Professor of Applied Mathematics at Dehradun Institute of Technology, Uttarakhand Technical University, Dehradun (Uttarakhand) INDIA. He obtained his Ph.D degree in Mathematics and master degree in Mathematics form DDU Gorakhpur University (UP) India. His research interests include operations research, modeling and simulation, economics and information system, graph theory and Finsler Geometry. He presented his research at several national and international conferences, and workshops on C++, finite element methods, MATLAB. His articles appeared in the Journal of Tamkang Journal of Mathematics, Taiwan, Republic of China, International Journal of Operations Research and Information System and many other reputed journals. He also published several books for engineering students. He has been teaching courses at Uttarakhand Technical University, Uttarakhand (INDIA) and received six appreciation letters for distinguishing teaching.

S.S.Misra is presently working as Scientist ' $D$ ' at Defence Research \& Development Organisation (DRDO) Headquarters, Govt. of India, New Delhi (India) in the area of R\&D Management. Before joining DRDO, he worked as Registrar in a Govt. Engineering College, i.e. Kamla Nehru Institute of Technology, Sultanpur, UP (India) and as Asstt. Manager (Technical) in a Govt. Financial Institution i.e U.P.Financial Corporation, Kanpur (India). He obtained Bachelors Degree in Civil Engineering from DDU Gorakhpur University (UP) India in year 1987 and Masters Degree in Financial Management from IGNOU, New Delhi (India) in year 1996. Currently he is doing his Ph.D. at Uttarakhand Technical University, Uttarakhand (India).

H.S.Shukla is presently working as Professor and head Department of Mathematics and Statistics , DDU Gorakhpur University ,Gorakhpur (UP),India.. He obtained his Ph.D degree in Mathematics and master degree in Mathematics form DDU Gorakhpur University (UP) INDIA. His research interests include operations research, Bio Mathematics and Finsler Geometry. He presented his research at several national and international conferences. His articles appeared in the Journal of Tamkang Journal of Mathematics, Taiwan, Republic of China and many other reputed journals. He also published several books for B.Sc. and M.Sc. students.

Received September 2010

Accepted December 2010

Final acceptance in revised form December 2010 